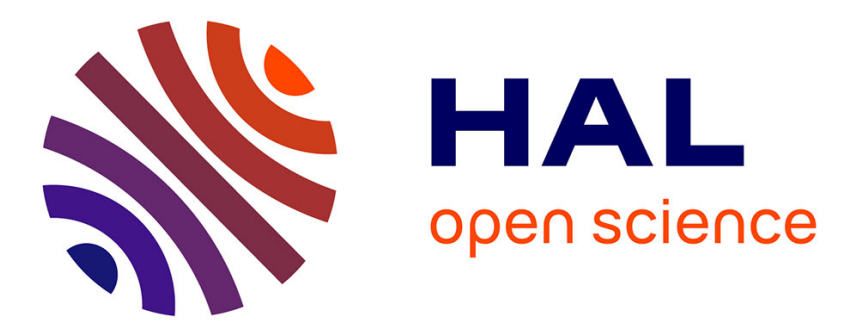

\title{
A comparative study on the hydro-mechanical behaviour of compacted bentonite/sand plug based on laboratory and field infiltration tests
}

Qiong Wang, Anh Minh A.M. Tang, Yu-Jun Cui, Jean-Dominique Barnichon, Wei-Min Ye

\section{To cite this version:}

Qiong Wang, Anh Minh A.M. Tang, Yu-Jun Cui, Jean-Dominique Barnichon, Wei-Min Ye. A comparative study on the hydro-mechanical behaviour of compacted bentonite/sand plug based on laboratory and field infiltration tests. Engineering Geology, 2013, 162, pp.79-87. 10.1016/j.enggeo.2013.05.009 . hal-00926865

\section{HAL Id: hal-00926865 \\ https://hal-enpc.archives-ouvertes.fr/hal-00926865}

Submitted on 26 Apr 2018

HAL is a multi-disciplinary open access archive for the deposit and dissemination of scientific research documents, whether they are published or not. The documents may come from teaching and research institutions in France or abroad, or from public or private research centers.
L'archive ouverte pluridisciplinaire HAL, est destinée au dépôt et à la diffusion de documents scientifiques de niveau recherche, publiés ou non, émanant des établissements d'enseignement et de recherche français ou étrangers, des laboratoires publics ou privés. 
6

7

8

9

10

11

12

13

14

15

16

17

18

19

20

21

22

23

24

25

26
A comparative study on the hydro-mechanical behaviour of compacted bentonite/sand plug based on laboratory and field infiltration tests

$$
\begin{aligned}
& \text { Qiong Wang }{ }^{1} \text {, Anh Minh Tang }{ }^{1} \text {, Yu-Jun Cui }{ }^{1,3} \text {, } \\
& \text { Jean-Dominique Barnichon }{ }^{2} \text {, Wei-Min } \mathrm{Ye}^{3}
\end{aligned}
$$

${ }^{1}$ Ecole des Ponts ParisTech, France

${ }^{2}$ Institut de Radioprotection et de Sûreté Nucléaire (IRSN), France

${ }^{3}$ Tongji University, China

\section{Corresponding author:}

Prof. Yu-Jun CUI

Ecole des Ponts ParisTech

6-8 av. Blaise Pascal, Cité Descartes, Champs-sur-Marne

77455 MARNE LA VALLEE

France

Telephone: +33164153550

Fax: +33164153562

E-mail: yujun.cui@enpc.fr 
Abstract: SEALEX is a research project aiming at identifying the key factors that affect the long-term performance of bentonite-based sealing systems with an initial technological void. In this context, a series of in-situ experiments have been being performed in field conditions. Meanwhile, a small scale test (1/10) was carried out in controlled conditions in the laboratory, aiming at providing useful information for analyzing the in-situ tests in terms of saturation time and sealing effectiveness. In this paper, the results of the small-scale test are presented along with the results from the first in-situ test (PT-N1). It was observed that during the saturation process, the evolution of the injected water volume followed a hyperbolic relationship with time in both the laboratory and field conditions. In the laboratory conditions, a decrease in axial swelling pressure occurred due to filling of the technological void. By contrast, this decrease has not been observed in the field conditions. Comparison of the injected water and the axial swelling pressure between the two different scales enabled the definition of a same time up-scaling ratio of 2.5 (in situ experiment /small scale test). Accordingly, the saturation duration of the in situ experiment was estimated to be equal to two years. For the small-scale test, a swelling strain evolution rate of 0.588 $\mathrm{mm} /$ day was identified in the case of infiltration from two sides of the sample. This is useful when predicting the evolution of swelling strain in the case of failure of the sealing plug. After filling of an additional $20 \%$ void, a swelling pressure of $0.18 \mathrm{MPa}$ was obtained, indicating the favorable sealing capacity of the material after filling the technological void.

Keywords: small-scale test; in-situ experiment; bentonite/sand mixture; technological 
void; swelling pressure; swelling stain.

\section{INTRODUCTION}

In the design of deep geological repository for high level long lived radioactive wastes, compacted bentonite-based materials are often considered as buffer/sealing materials.

These materials are expected to exhibit a swelling pressure high enough to fulfil their buffer/sealing functions.

Numerous laboratory studies have been conducted to assess the performance of buffer/sealing materials (e.g. Delage et al., 1998; Lloret et al., 2003; Romero et al., 2005; Lloret \& Villar, 2007). Various experiments were also performed in the underground research laboratories (URL) (TSX at Manitoba, Canada; FEBEX at Grimsel, Switzerland; RESEAL at Mol, Belgium; KEY at Bure, France, etc.). Recently, IRSN (Institut de Radioprotection et de Sûreté Nucléaire, France) has launched the SEALEX project aiming at identifying and quantifying the key factors related to the long-term performance of bentonite-based sealing systems taking into account an initial technological void. This project consists of a series of in-situ experiments in the Tournemire URL, and a small-scale test (1/10) in the laboratory.

The in-situ experimental program was purposefully built allowing systematical exploration of the effects of technical specifications, design, construction, defect, etc., by changing a single parameter each time. As a reference case (see Barnichon et al. 2009, 2012 for more details), the first test PT-N1 with a clay core made up of pre-compacted monolithic disks of MX80 bentonite/sand mixture (70/30 in dry mass) 
has been conducted in the URL of Tournemire. Due to the low permeability of this material, saturation is expected to be reached in several years (see Barnichon et al., 2012). During the saturation process, the injected water volume, total pressure, pore water pressure and relative humidity changes have been monitored at several positions within the plug. After the saturation stage, hydraulic tests will be performed to determine the overall hydraulic properties (permeability, occurrence of leakage) of the sealing system. In addition to this reference case, three other tests are designed to quantify the impact of the technical specification and design of the sealing plug by changing the intra-core geometry (jointed in stead of monolithic disks), core composition (MX80/sand ratio) and core conditions (compacted in field in stead of pre-compacted). Moreover, to investigate the effect of altered conditions, an additional test is designed to simulate an incidental decrease of swelling pressure caused by failure of the confining structure.

Based on the design of the in-situ experiments, a laboratory small-scale test (1/10) was performed, focusing on the recovery capacity of the bentonite-based seal with technological voids. The material identical to that used in test PT-N1 was used (MX80 bentonite/sand mixture). A confining cell of stainless steel was used to simulate the constant-volume boundary conditions. After the initial saturation process as in the PT-N1 in-situ experiment, the seal evolution upon a confinement failure was simulated by allowing a given amount of free swell. This free swell was followed by a last stage of wetting under constant volume conditions. To assess the sealing capacity, the injected water volume, axial swelling pressure and swelling strain were monitored 
in different stages. It was expected to obtain useful information from the laboratory small-scale test for analysing the field tests in terms of saturation time and sealing effectiveness.

In this paper, the results of the small scale test are presented along with the results from the in-situ test (PT-N1). An up-scaling ratio was obtained by comparing the injected water volume and the axial swelling pressure evolution between the laboratory and field conditions. The time needed to reach the stabilization of axial swelling pressure for the in situ test (PT-N1) as well as the evolution of swelling strain and swelling pressure in the case of failure of the confining structure were estimated accordingly.

\section{MATERIALS AND METHODS}

\subsection{Materials}

The soil studied is a compacted MX80/sand mixture with a proportion of 70/30 in dry mass. The bentonite is from Wyoming, USA, with a high content of montmorillonite (80\%). It has a liquid limit of $575 \%$, a plastic limit of $53 \%$ and a unit mass of $2.77 \mathrm{Mg} / \mathrm{m}^{3}$. The cation exchange capacity (CEC) is $76 \mathrm{meq} / 100 \mathrm{~g}\left(83 \%\right.$ of $\left.\mathrm{Na}^{+}\right)$. The quartz sand used in the mixture comes from Eure and Loire (France) with a unit mass of $2.65 \mathrm{Mg} / \mathrm{m}^{3}$. It was sieved at $2 \mathrm{~mm}$ prior to being mixed with the bentonite.

The water used has the same chemical composition as the pore water of the Callovo-oxfordian claystone from the ANDRA URL in Bure (France), namely synthetic water (Wang et al., 2012a, 2012b). It was obtained by mixing the 
corresponding chemical compounds (see Table 1) with distilled water using a magnetic stirrer until full dissolution.

\subsection{SEALEX in-situ test (PT-N1)}

As mentioned above, the in-situ experiment (PT-N1) has been conducted in the Tournemire Underground Research Laboratory excavated in Toarcian claystone. A horizontal borehole $(0.60 \mathrm{~m}$ in diameter) was drilled for this purpose. Figure 1 shows the layout of the experiment. A seal made up of compacted MX80/sand mixture was sandwiched between two porous plates, allowing water inflow from two water reservoirs (i.e. upstream and downstream). The $14.33 \%$ annular technological void (volume of void/volume of borehole) was defined by adopting a smaller initial diameter $(0.555 \mathrm{~m})$ of the pre-compacted seal as compared to the borehole diameter $(0.60 \mathrm{~m})$. The upstream plate is in direct contact with the host-rock while the downstream one is retained by a confining system ensuring a constant-volume condition. A packer-like device was used to prevent water leakage from the interface between the confining plug and host-rock.

The clay seal in test PT-N1 is made up of 8 monolithic pre-compacted disks $(0.555 \mathrm{~m}$ in diameter and $0.15 \mathrm{~m}$ thick) of MX80/sand mixture with an initial dry density of $1.97 \mathrm{Mg} / \mathrm{m}^{3}$ (Figure 2). The disks were arranged in vertical slices giving rise to the geometry of seal as shown in Figure 2. The bricks were obtained through uniaxial compaction of the mixture at its initial water content of $11 \%$. The initial dry density $\left(1.97 \mathrm{Mg} / \mathrm{m}^{3}\right)$ of the bricks was selected based on the consideration of the $14.33 \%$ technological void and the need to have a final dry density of $1.67 \mathrm{Mg} / \mathrm{m}^{3}$ after 
saturation of the plug and filling of the initial technological voids.

Three types of sensors were installed within the compacted blocks to monitor the swelling pressure, pore pressure and relative humidity. For clarity, only the distribution of sensors for swelling pressure measurement is shown in this paper (Figure 3a). Three total pressure sensors were installed on the surface of the column at section $0.60 \mathrm{~m}$ (from the downstream saturation system, L-01, L-02, L-03) to measure the radial swelling pressure; two total pressure sensors were installed at section 0 and $1.20 \mathrm{~m}$ to measure the axial swelling pressure (A-01, A-02). For each sensor, a hole as shown in Figure $3 \mathrm{~b}$ was prepared at their pre-assigned positions before the assemblage of blocks, keeping the hole to a minimum size. Wireless sensors $(d=32$ $\mathrm{mm}$ ) were used to limit preferential flow along cables and a wireless transmitter was installed at each measurement section. Data were recorded automatically by a data acquisition system.

Regarding the test operational phases, a volume of water of $49 \mathrm{~L}$ was first injected, which corresponded to the volume of the technological void adopted. This process ended in one hour. Afterwards, the water supply was stopped because the side packer was not properly inflated; it restarted after 20 days under a water pressure of $0.1 \mathrm{MPa}$. During the saturation process, the swelling pressure, pore pressure, water content or water saturation within the plug were monitored. The injected water volumes at both upstream and downstream chambers were also measured. When the saturation process is completed, hydraulic tests will be performed to determine the overall hydraulic properties (permeability, occurrence of leakage) of the corresponding sealing systems. 


\subsection{Laboratory small-scale test}

158 The experimental devices used for the laboratory small-scale test $(1 / 10)$ are shown in

159 Figure 4. A stainless steel cell of $60 \mathrm{~mm}$ in inner diameter and $200 \mathrm{~mm}$ long was used.

160 As in the in-situ test, an annular technological void was defined by adopting a smaller

161 initial diameter $(55.5 \mathrm{~mm})$ for the pre-compacted sample as compared to the diameter

162 of the hydration cell $(60 \mathrm{~mm})$. Note however that the hydration cell was placed in the

163 vertical direction (see Figure 4) and it was then different from the in-situ test which is

164 performed in a horizontal borehole (see Figure 1 and Figure 2). Water supply was

165 conducted through the water inlets in the bottom base which was connected to

166 burettes. This allowed measurement of the total amount of water taken up by the

167 sample. A piston of $60 \mathrm{~mm}$ diameter was used to simulate the confining structure. On

168 the bottom of the piston, there was drainage with two inlets (upside inlet in Figure 4)

169 and a porous stone of $50 \mathrm{~mm}$ diameter, allowing water/air flow. A mechanical press

170 was used to restrain the axial deformation and a force transducer was used to monitor

171 the axial swelling pressure. A displacement transducer fixed on the piston allowed

172 monitoring of the axial displacement to an accuracy of $1 \mu \mathrm{m}$. The axial pressure and

173 axial displacement were recorded automatically to a data logger, while the inlet water

174 volume was measured manually by determining the water level in the burettes. Note

175 that in this small-scale test, the radial swelling pressure was not measured.

176 A monolithic cylindrical sample (55.5 $\mathrm{mm}$ in diameter, $120 \mathrm{~mm}$ high) was used in the

177 test. It was statically compacted in a mould to the same dry density as in the in-situ

178 test $\left(1.97 \mathrm{Mg} / \mathrm{m}^{3}\right)$. In order to ensure the homogeneity of the specimen, the 
compaction was carried out in two layers. The surface of the first compacted layer was carefully scarified before the second layer was added to ensure a good junction between them. Figure 5a shows the pre-compacted specimen with the hydration cell. After compaction, the specimen $(55.5 \mathrm{~mm}$ in diameter) was placed at the center of the cell $(60 \mathrm{~mm}$ in inner diameter), leaving an annular void $(2.25 \mathrm{~mm})$ between the specimen and cell wall (Figure 5b). An initial axial stress of $0.1 \mathrm{MPa}$ was applied on the specimen before hydration in order to ensure good contacts between the load cell and the piston, between the piston and the sample, between the sample and the cell bottom, as well as satisfactory load measurement. Then, the upside inlets (see Figure 4) were sealed and vacuum was applied to evacuate all air in the voids (technological void mainly). The synthetic water was finally injected from the bottom.

As described in Figure 6, hydration was carried out in three stages. First, the axial deformation was restrained and water was injected to the sample; during this stage (Stage 1. initial saturation phase), the evolution of the vertical swelling pressure was monitored. Once the hydration ended, the confining pressure in the axial direction was removed by unloading, allowing a free swell of $20 \%$ (Stage 2. recovery of the void phase). To reduce the test duration in this stage, two-side infiltration was applied by injecting water from both the bottom and the top, while recording changes in axial swelling strain over time. This stage aimed at simulating the case of a saturation defect or a failure of confining structure that may occur during the long-term lifespan of the disposal system. The free swell of $20 \%$ represents the sealing capacity required after filling the technological void. When the axial swelling strain reached the desired 
value of $20 \%$, the piston was automatically blocked thanks to a reserved distance of $24 \mathrm{~mm}$ (corresponding to $20 \%$ swelling strain) between the piston and the load cell (Figure 7); the evolution of swelling pressure was monitored again (Stage 3. confinement phase).

\section{EXPERIMENTAL RESULTS}

\subsection{In situ test (PT-N1)}

Figure 8 shows the evolution of injected water volume over time. As mentioned above, a volume of $49 \mathrm{~L}$ was first injected to fill the technological void and the injection was stopped for 20 days due to a technical problem related to the packer. After resuming the injection, it was observed that the increase rate of water volume was followed by an asymptotic curve with a decreasing rate. After 367 days, the total injected water volume was $71.39 \mathrm{~L}$ (Figure 8). Examination of the curve shows that the shape of water volume versus time (after rejection) can be described by a hyperbolic function. Figure 9 presents the time/water volume (day/L) versus time. A good linear relationship is obtained, confirming that the water volume-time curve is of a hyperbolic shape. Thereby, the following equation can be adopted for this relationship:

where $t$ is time, $V$ is injected water volume, $a$ and $b$ are the intercept and the slope of the straight line, respectively (Figure 9).

According to this hyperbolic relationship, the maximum water volume corresponds to 
$1 / b$ (Eq.2), equal to $72.46 \mathrm{~L}$. This is to be compared with the total volume of voids including the technological void and the soil porosity: $69.1 \mathrm{~L}$.

$$
V_{\text {max }}=\lim _{t \rightarrow \infty} V(\mathrm{t})=\lim _{t \rightarrow \infty}\left(\frac{1}{\mathrm{a} / \mathrm{t}+\mathrm{b}}\right)=\frac{1}{b}
$$

During hydration, both the axial and radial swelling pressures were recorded by the total pressure sensors (see Figure 3) and the results are shown in Figure 10. The data by the sensor located at $1.20 \mathrm{~m}$ section for the axial swelling pressure measurement were unfortunately not available; only the axial swelling pressure values at $0 \mathrm{~m}$ section are presented. This pressure increased at an almost constant rate and reached 1.63 MPa after 367 days. For the radial swelling pressure, the evolution rates were very different for the three sensors (see Figure 3); the pressure values reached were 1.78 MPa, 0.56 MPa and 1.05 MPa for sensors L-01, L-02 and L-03, respectively. This indicates the heterogeneous radial swelling under the in-situ conditions.

\subsection{Small-scale test}

Figure 11 shows the measured water inflow over time. Once the water supply was connected to the bottom inlet, water volume increased rapidly and reached $49 \mathrm{~mL}$ in a few minutes. This value corresponded exactly to the volume of technological void (49 $\mathrm{mL})$. Afterwards, water volume increased gradually to reach a maximum value of $70.6 \mathrm{~mL}$. No more water could infiltrate after about 200 days. The total volume of void (including the technological void $\mathrm{V}_{\text {tech }}$ and the void inside the soil $\mathrm{V}_{\mathrm{v}-\mathrm{s}}$ ) that could be filled with water was estimated at $69.1 \mathrm{~mL}$. The result shows that a little more water was injected with respect to the estimated one (70.6 mL against $69.1 \mathrm{~mL})$, 
but the difference is quite small.

244 For further analyzing the evolution of water volume, the time/water volume (day $/ \mathrm{mL})$

245 is plotted versus time in Figure 12. As in the case of in-situ test, a straight line is 246 obtained justifying a hyperbolic relationship between the water volume and the 247 elapsed time (Eq.1). The value of 1/b corresponds to the maximum volume of water: $2481 / b=71.43 \mathrm{~mL}$, which is very close to the measured water volume $(70.6 \mathrm{~mL})$. Figure 13 and Figure 14 depict the evolution of swelling pressure in the first stage (i.e.

250 initial saturation phase). Once water was injected into the specimen, the axial swelling 251 pressure increased very quickly (Figure 14). After about 2 days, the swelling pressure reached a first stability stage $(1.30 \mathrm{MPa})$ and it restarted to increase on the $4^{\text {th }}$ day. When the swelling pressure reached $1.45 \mathrm{MPa}$ after about 12 days, a significant 254 decrease of swelling pressure occurred and a minimum value of $0.70 \mathrm{MPa}$ was reached. Afterwards, the swelling pressure increased again after about 33 days (Figure however that the variation of displacement was smaller than $0.2 \mathrm{~mm}$. It represents $0.16 \%$ of the specimen height $(120 \mathrm{~mm})$, suggesting a satisfactory control of axial displacement in this stage. 
According to the data obtained in the first stage (Figure 13), no obvious swelling pressure increase occurred during a period of 50 days from day 300 to day 350 . Thus, it was decided to start the second stage. For this purpose, the confining pressure was removed on day 350, allowing the free swell. Changes in axial swelling strain were recorded and presented in Figure 15. The uplifting of load cell led to an instantaneous rebound of $1.1 \%(1.4 \mathrm{~mm} / 120 \mathrm{~mm})$. Afterwards, the axial swelling strain increased almost linearly at a rate of $0.145 \mathrm{~mm} /$ day. Following this rate, $20 \%$ of swelling strain was expected to be reached after 157 days. In order to reduce the test duration, two sides infiltration was applied on day 364. This resulted in an increase of the swelling strain rate to $0.588 \mathrm{~mm} / \mathrm{day}$, which is four times faster than that with one-side infiltration. The expected value of $20 \%$ (24 mm) was reached on day 400 . The piston was then re-blocked automatically to start Stage 3. Note that the measured axial swell was $24.4 \mathrm{~mm}$.

The evolution of swelling pressure was then measured again and the results are presented in Figure 16. Small fluctuation was observed and this fluctuation can be attributed to the daily temperature variations. As expected, the evolution curve follows a hyperbolic curve with a decreasing rate over time. It reached stabilization on day 520 with a final swelling pressure of $0.18 \mathrm{MPa}$.

\section{COMPARISON AND DISCUSSION}

It was observed that more water infiltrated into the soil than that calculated by considering the technological void and the soil porosity in both the in situ test 
(71.39 L) and laboratory small-scale test $(70.60 \mathrm{~mL})$. Even though the water volume has been not yet reached stabilization in the in-situ conditions, the discrepancy is found to be larger than in the small-scale test. This can be related to the natural conditions of the in-situ test, where some water intake by the host-rock did occur. With a well controlled condition in the small-scale test, the larger infiltrated water obtained may be related to the low water density $\left(1.00 \mathrm{Mg} / \mathrm{m}^{3}\right)$ considered in the determination of soil void ratio. Indeed, for high plasticity materials as the MX80 bentonite, the water density can be much higher than $1.00 \mathrm{Mg} / \mathrm{m}^{3}$ (Marcial 2003, Villar and Lloret 2004, Lloret and Villar 2007, Jacinto et al. 2012). This is in agreement with the observation from the KBS-3H mock-up test (Börgesson et al. 2005).

Regarding the evolution of water volume, a hyperbolic relationship between the injected water volume and elapsed time was obtained in both tests. Accordingly, the maximum water volume was estimated at $72.46 \mathrm{~L}$ and $71.43 \mathrm{~mL}$ for the in-situ and small-scale tests, respectively. To compare the evolution curve at different scales, the water volume was normalized by using these two values. The normalized water volume is equal to the ratio of water volume at time $t\left(V_{t}\right)$ to the maximum water volume that can be injected $(72.46 \mathrm{~L}$ and $71.43 \mathrm{~mL}$ for the in-situ and small-scale test, respectively). In terms of time scale, an up-scaling ratio of 2.5 (in situ test/small scale test) was found from the normalized water volume shown in Figure 17, where very similar evolution curves (normalized water volume versus normalized time) were obtained for the two tests (in situ and small scale tests). 
This up-scaling ratio is much smaller than that estimated based on the consolidation theory by considering the experiment scale and hydration conditions: according to the

309 infiltration length, the hydration rate of the in-situ test should be 100 times lower than 310 in the small-scale test (1/10). As the two-side infiltration applied in the in-situ test 311 increased the hydration rate by 4 times, the up-scaling ratio should be equal to 25 312 (in-situ test / small scale test), still ten time larger than the rate identified from the 313 measurements. In fact, under the field conditions, water may fill some voids between 314 the pre-compacted disks during the first minutes $(0.15 \mathrm{~m}$ thick, see Figure 2$)$. This 315 infiltration length of $0.15 \mathrm{~m}$ leads to an up-scaling ratio to 0.56 . The up-scaling ratio of 2.5 observed is possibly related to the combined effect of these two phenomena.

Using this up-scaling ratio, the axial swelling pressure evolution curve obtained from the in-situ test (Figure 10) was normalized and presented in Figure 18, together with the axial swelling pressure measured in the first stage of the small-scale test. Except for the first 33 days (see Figure 13) where significant decrease of swelling pressure occurred in the small-scale test, the normalized curve of swelling pressure for the in-situ test join the curve of the small-scale test, confirming the up-scaling ratio of 2.5. Based on the results of small-scale test, this ratio allows the time needed to reach the stabilization of swelling pressure in the in-situ test to be estimated. It can be observed normalized time scale for the in-situ test. Accordingly, it can be estimated that the maximum swelling pressure in the in-situ test should be reached after 388 days, 
corresponding to 754 days starting from the time of water injection.

As regards the kinetics of the axial swelling pressure in the first 33 days of small-scale test, stabilization was attained after about 2 days at $1.30 \mathrm{MPa}$ and restarted to increase from day 4 (Figure 14). Wang et al. (2012b) observed similar phenomenon in swelling pressure tests on smaller samples (35 $\mathrm{mm}$ in diameter, $10 \mathrm{~mm}$ in height) with the same percentage of technological void. This is related to changes in microstructure of soil. With the progress of hydration, the effect of microstructure changes is reduced, resulting in the re-increase in swelling pressure (Cho et al., 2000; Baille et al., 2010). When the swelling pressure reached $1.45 \mathrm{MPa}$ on day 12 , a significant decrease of swelling pressure occurred, reaching a minimum value of $0.70 \mathrm{MPa}$. This decrease can be attributed to the filling of the technological void. Afterwards, the swelling pressure increased again from day 33. However, the evolution curve showed fluctuation due to the re-organization of soil microstructure under the effect of technological void.

On the contrary, the axial swelling pressure measured in the in-situ test increased constantly without any fluctuation. This can be related to a coupled effect of large scale and pressure sensor location. Indeed, in the small-scale test, the axial swelling pressure was measured on the whole cross section and any changes in axial pressure could be monitored. However, in the in situ test, the total pressure sensor was installed in the centre of the cross section (Figure 3) and the axial swelling pressure herein corresponded to the local one. Therefore, the axial swelling pressure changes occurred in the zone of technological void could not be detected by this sensor. 
After the axial swelling pressure of small-scale test reached stabilization, removing the axial confining restriction led to a very small rebound of $1.1 \%(1.4 \mathrm{~mm} / 120 \mathrm{~mm})$. This observation provides valuable information for the confinement removal phase of the in-situ test. During the free swelling process (Stage 2), a swelling strain evolution rate (swelling strain/time) of $0.588 \mathrm{~mm} /$ day was observed under two-side infiltration conditions. Combined with the up-scaling ratio, this result $(0.588 \mathrm{~mm} /$ day $)$ allows prediction of the swelling strain evolution in the in-situ test when simulating an incidental decrease of the swelling pressure caused by a failure of the concrete confining structure.

As the piston was re-blocked automatically in the small-scale test (Stage 3), swelling pressure developed again. This indicates the favorable sealing capacity after filling of the technological void. If a saturation defect or a confining structure failure occurs in the field, a $20 \%$ additional void could be sealed. A final swelling pressure of $0.18 \mathrm{MPa}$ was attained, which is in accordance with the swelling pressures measured in the laboratory on smaller samples (Wang et al., 2012b): after the $20 \%$ free swell $(24.5 \mathrm{~mm})$, the dry density decreased to a final value of $1.39 \mathrm{Mg} / \mathrm{m}^{3}$; this corresponds to a swelling pressure of $0.23 \mathrm{MPa}$.

\section{CONCLUSION}

In the context of SEALEX project, a laboratory small-scale test (1/10) was carried out to investigate the recovery capacity of bentonite-based plug with technological void. By comparison with the first results from the in-situ test PT-N1, the phenomena 

the in-situ test.

During the saturation process, a hyperbolic relationship between the injected water volume and elapsed time was obtained in both laboratory and field tests. However, a little more water was injected as compared to the water volume estimated by considering the total porosity. Larger discrepancy was found for the in-situ test due to the effect of natural conditions.

Decrease of axial swelling pressure was observed in the small-scale test due to the increased continually in the in-situ test. This could be attributed to the effects of both the scale and the locations of pressure sensors.

Comparison of the injected water volume and the axial swelling pressure between the two different scales gave the same up-scaling ratio of 2.5 (in-situ scale / laboratory scale). Using this up-scaling ratio, the time needed to reach the swelling pressure stabilization in the in-situ test was estimated at 754 days.

387 After removal of the axial confining restriction, a swelling strain evolution rate 388 (swelling strain/time) of $0.588 \mathrm{~mm}$ /day was observed in the case of two-side 389 infiltration. Combined with the up-scaling ratio, this rate allowed prediction of the 390 swelling strain evolution in case of a confining structure failure. A swelling pressure 391 of $0.18 \mathrm{MPa}$ was obtained after filling an additional void of $20 \%$, indicating the favorable sealing capacity after filling the technological void. 


\section{ACKNOWLEDGEMENTS}

The work was conducted in the framework of the SEALEX project carried out by

IRSN, with collaboration of the Canadian Nuclear Safety Commission. The supports from the China Scholarship Council (CSC) and from the PHC Cai Yuanpei project (24077QE) are also greatly acknowledged.

\section{REFERENCES}

Baille, W., Tripathy, S. \& Schanz, T. 2010. Swelling pressures and one-dimensional compressibility behaviour of bentonite at large pressures. Applied Clay Science, Vol 48, 324-333

Barnichon, J.D. \& Deleruyelle, F. 2009. Sealing Experiments at the Tournemire URL. EUROSAFE.

Barnichon, J.D., Dick, P. \& Bauer, C. 2012. The SEALEX in situ experiments: performance test of repository seals. Harmonising Rock Engineering and the Environment - Qian \& Zhou (eds) Taylor \& Francis Group, London. ISBN 978-0-415-80444-8, pages 1391-1394.

Börgesson, L., Sandén, T., Fälth, B., Åkesson, M. \& Lindgren, E. 2005. Studies of Buffers Behaviour in KBS-3H Concept: Work During 2002-2004, SKB, R-05-50.

Cho, W.J., Lee, J.O., \& Kang, C.H. 2000. Influence of temperature elevation on the sealing performance of a potential buffer material for a high-level radioactive waste repository. Annals of Nuclear Energy, Vol 27, 1271-1284

Delage, P., Howat, M.D. \& Cui., Y.J. 1998. The relationship between suction and swelling properties in a heavily compacted unsaturated clay. Engineering Geology, 50(1-2), $31-48$.

Jacinto, A.C., Villar, M.V. \& Ledesma, A. 2012. Influence of water density on the water-retention curve of expansive clays, Ge'otechnique 62, No. 8, 657-667

Lloret, A., Villar, M.V., Sánchez, M., Gens, A., Pintado, X. \& Alonso, E.E. 2003. Mechanical behaviour of heavily compacted bentonite under high suction changes. Ge'otechnique 53, No. 1, 27-40

Lloret, A. \& Villar, M. 2007. Advances on the knowledge of the thermo-hydro-mechanical behaviour of heavily compacted FEBEX bentonite. Physics and Chemistry of the Earth, $32,701-715$

Marcial, D. 2003. Comportement hydromécanique et microstructural des matériaux de barrière ouvragée, PHD thesis, École Nationale des Ponts et Chaussées, Paris, France.

Romero, E., Villar, M. V. \& Lloret, A. 2005. Thermo-hydro-mechanical behaviour of heavily overconsolidated clays. Engng Geol. 81(3): 255 - 268.

Villar, M.V. \& Lloret, A. 2004. Influence of temperature on the hydro-mechanical behaviour of a compacted bentonite. Applied Clay Science, 26(1-4), 337-350.

Wang, Q., Tang, A. M., Cui, Y.J., Delage, P. \& Gatmiri, B. 2012a. Experimental study on the 

swelling behaviour of bentonite/claystone mixture, Engineering Geology, Vol. 124, $59-66$.

433 Wang, Q., Tang, A. M., Cui, Y.J., Delage, P., Barnichon, J.D. \& Ye, W.M. 2012b. The effects of technological voids on the hydro-mechanical behaviour of compacted bentonite-sand mixture. Soils and Foundations, Vol. 53(2), 232-245.. 
Table 1. Chemical composition of the synthetic water.

\section{$440 \quad$ List of Figures}

Figure 1. Layout of the SEALEX in-situ experiment (after Barnichon and Deleruyelle, 2009)

Figure 2. Geometry of the clay plug and the compacted bricks

Figure 3. Distribution and installation of the total pressure sensors

Figure 6. A schematic description of the three stages of the small scale test

Figure 7. Lifting of load cell for free swell

449 Figure 8. Injected water volume versus time

450 Figure 9. Time/water volume versus elapsed time after water rejection

451 Figure 10. Evolution of swelling pressure

452 Figure 11. Water volume injected into the specimen

453 Figure 12. Time/water volume versus elapsed time

454 Figure 13. Evolution of axial swelling pressure and displacement in the first stage

455 Figure 14. Evolution of swelling pressure during the first 33 days

456 Figure 15. Evolution of axial swelling strain during Stage 2

457 Figure 16. Evolution of axial swelling pressure during Stage 3

458 Figure 17. Normalized water volume versus normalized time

459 Figure 18. Swelling pressure versus normalized time 
Table 1. Chemical composition of the synthetic water.

\begin{tabular}{lccccccc}
\hline Compound & $\mathrm{NaHCO}_{3}$ & $\mathrm{Na}_{2} \mathrm{SO}_{4}$ & $\mathrm{NaCl}$ & $\mathrm{KCl}$ & $\mathrm{CaCl}_{2} \cdot 2 \mathrm{H}_{2} \mathrm{O}$ & $\mathrm{MgCl}_{2} \cdot 6 \mathrm{H}_{2} \mathrm{O}$ & $\mathrm{SrCl}_{2} \cdot 6 \mathrm{H}_{2} \mathrm{O}$ \\
\hline $\begin{array}{l}\text { Mass (g) per Litter } \\
\text { of solution }\end{array}$ & 0.28 & 2.216 & 0.615 & 0.075 & 1.082 & 1.356 & 0.053 \\
\hline
\end{tabular}

463

464

465

466 


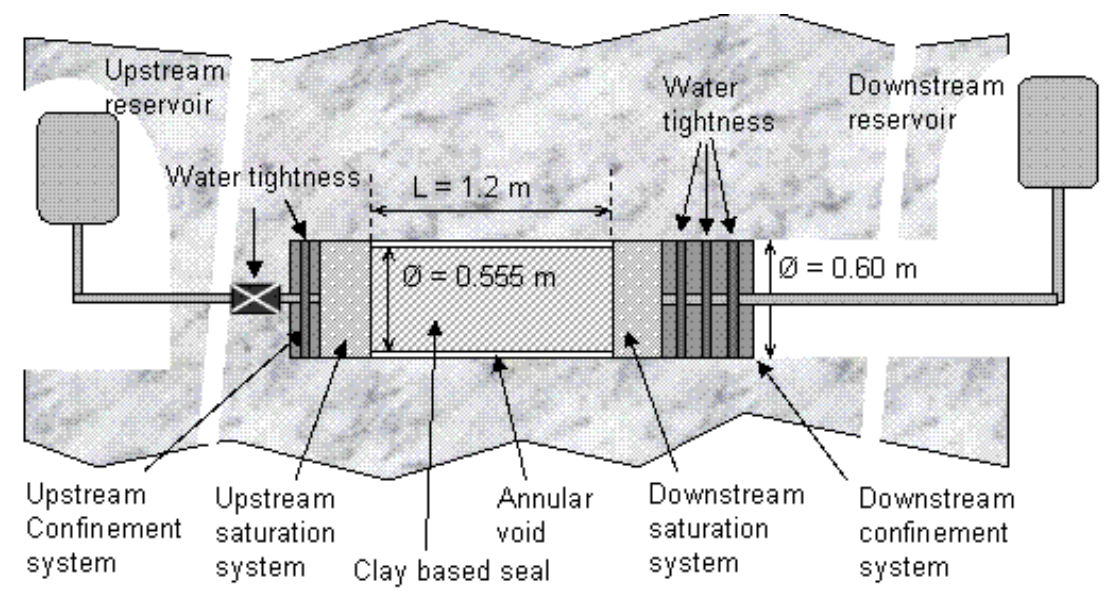

470 Figure 1. Layout of the SEALEX in-situ experiment (after Barnichon and Deleruyelle, 2009).

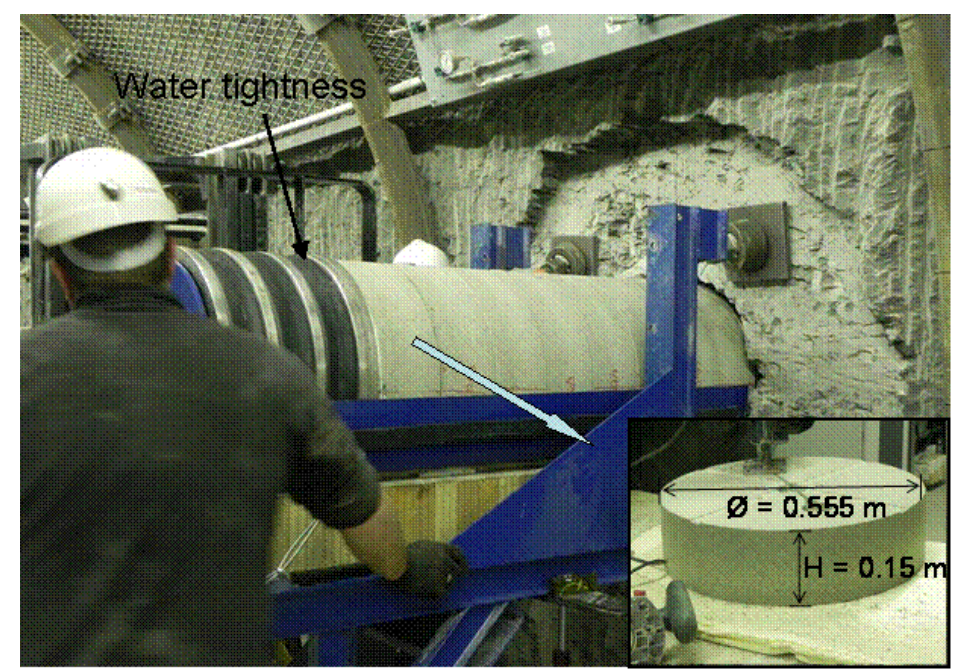

Figure 2. Geometry of the clay plug and the pre-compacted blocks. 


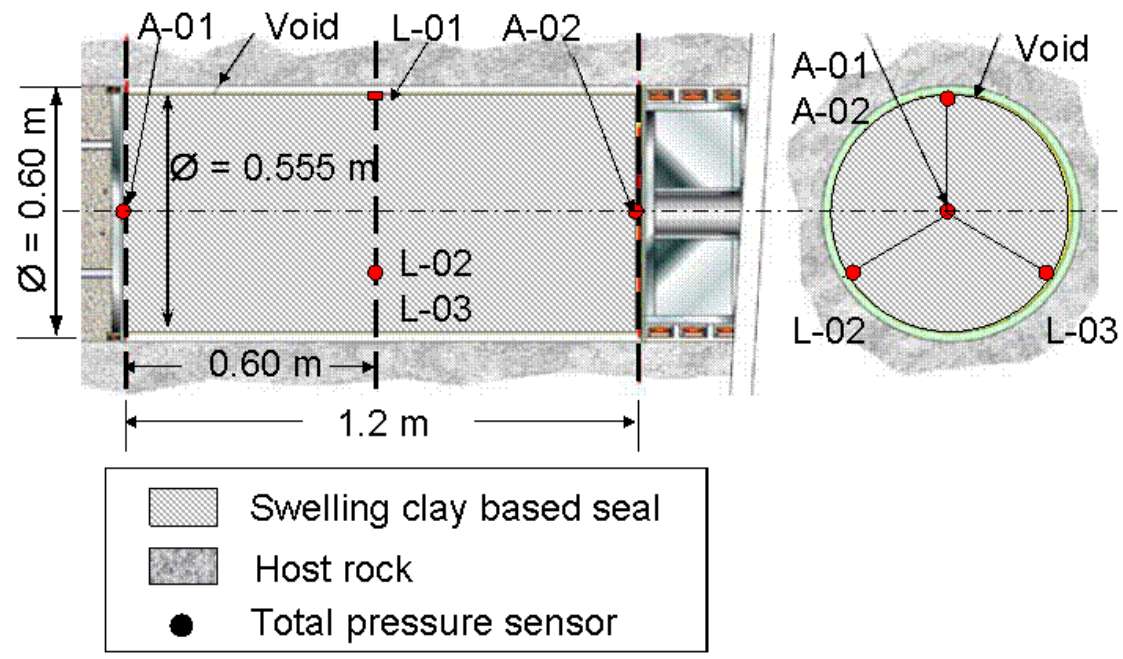

(a) Distribution of the total pressure sensors

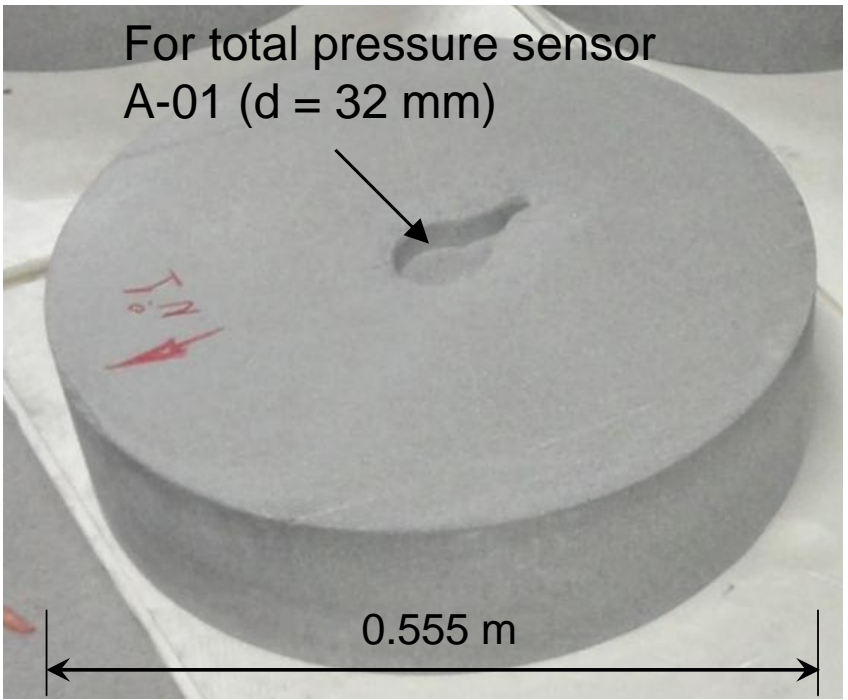

(b) Hole machined for installation of wireless sensor

Figure 3. Distribution and installation of the total pressure sensors. 

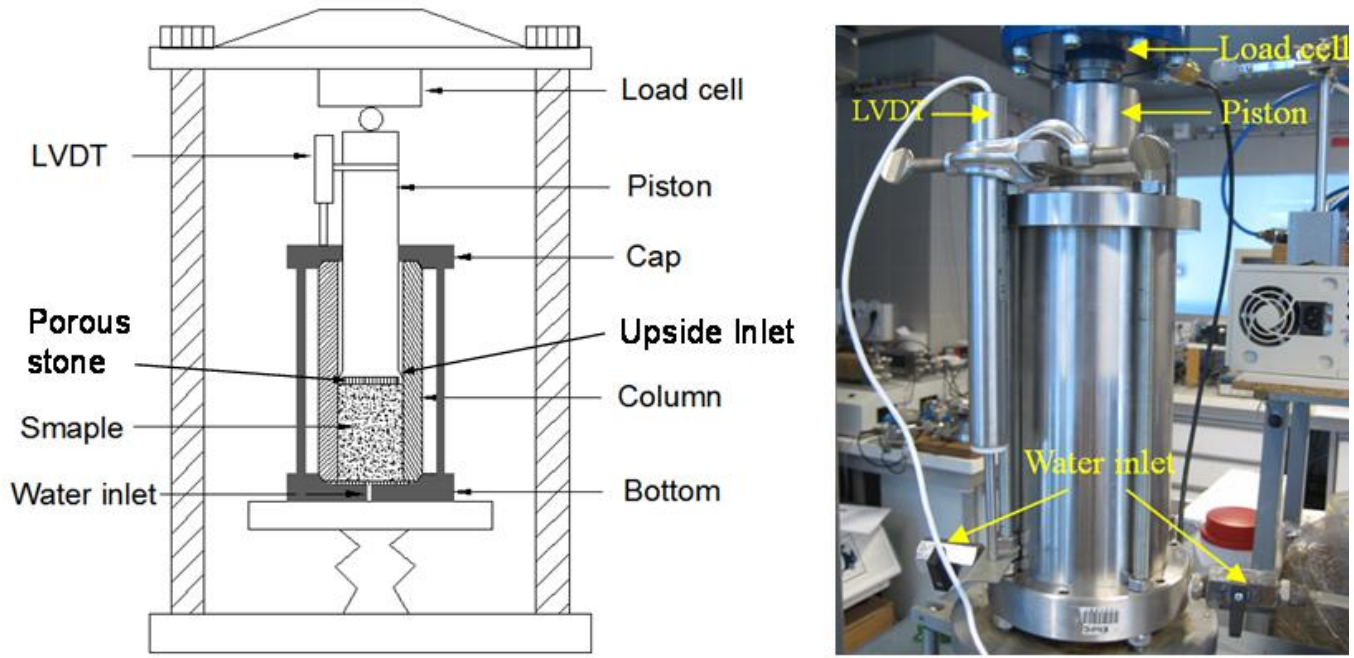

Figure 4. Experimental devices.

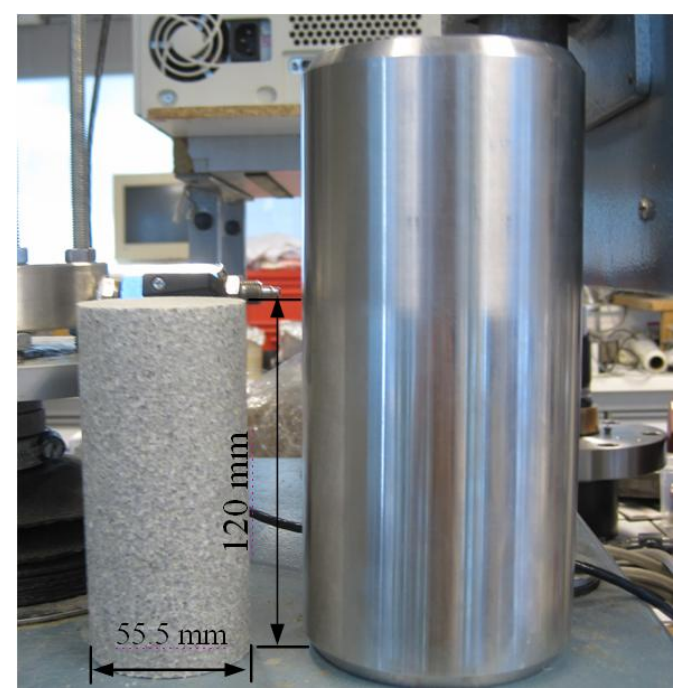

(a)

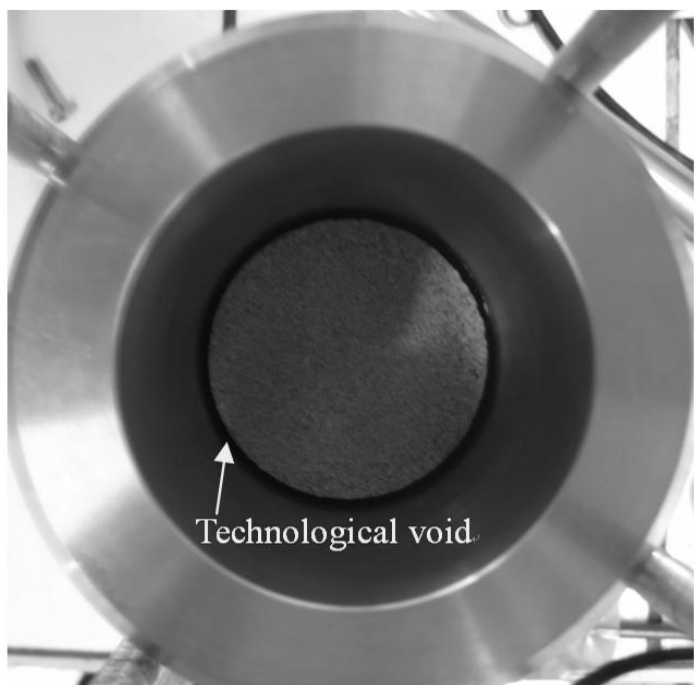

(b)

Figure 5. Sample preparation.

486 
(1) Initial saturation (2) Recovery of void (3) Confinement

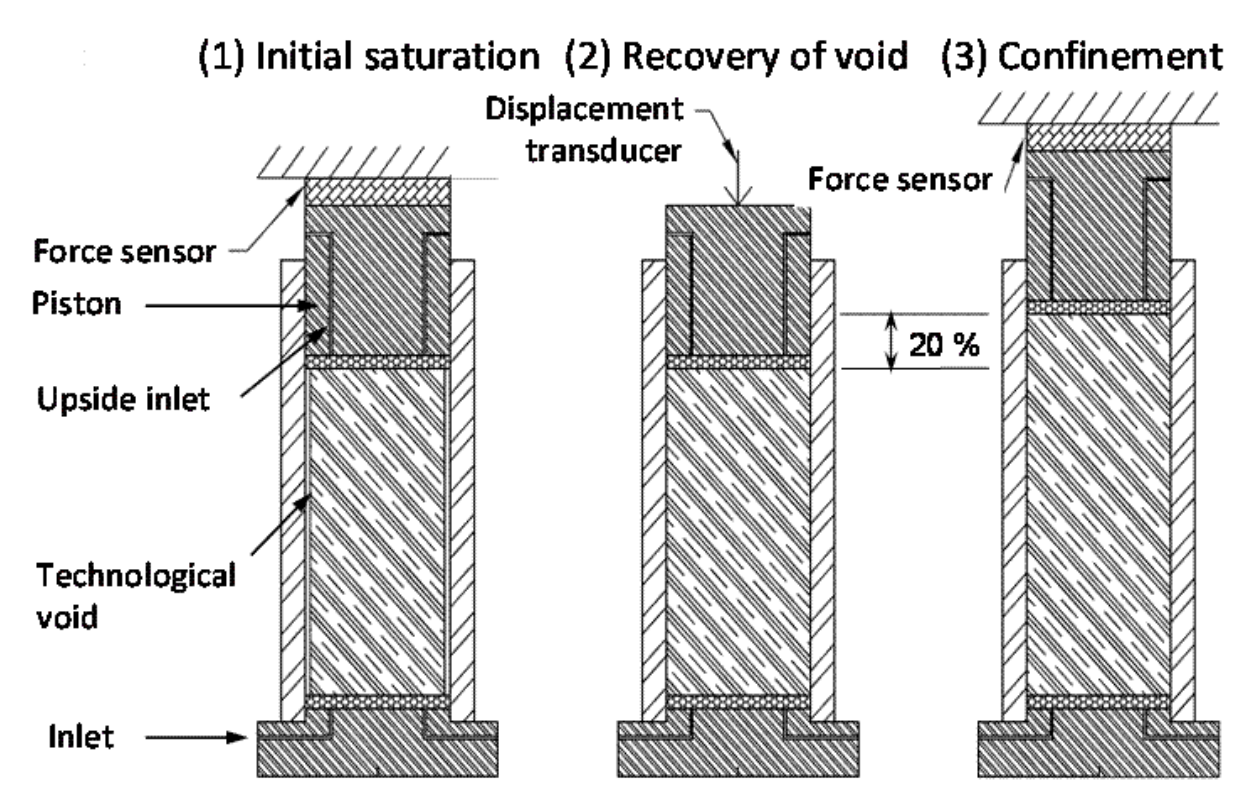

Figure 6. A schematic description of the three stages of the small-scale test.

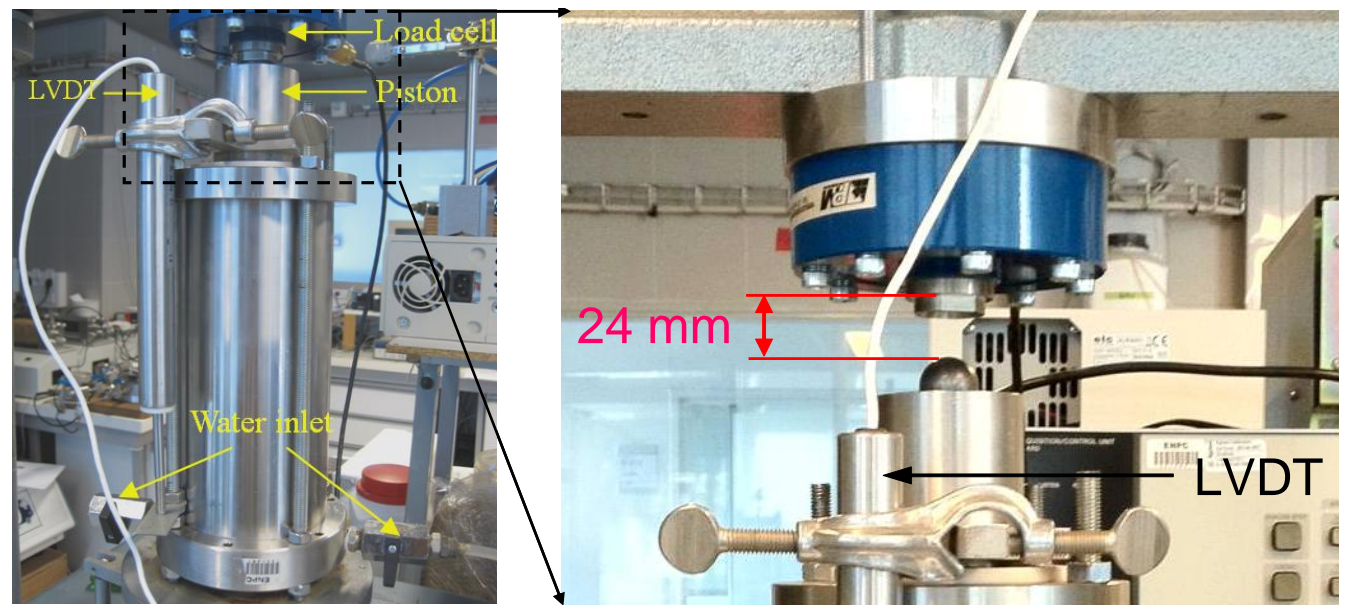

Figure 7. Lifting of load cell for free swell. 


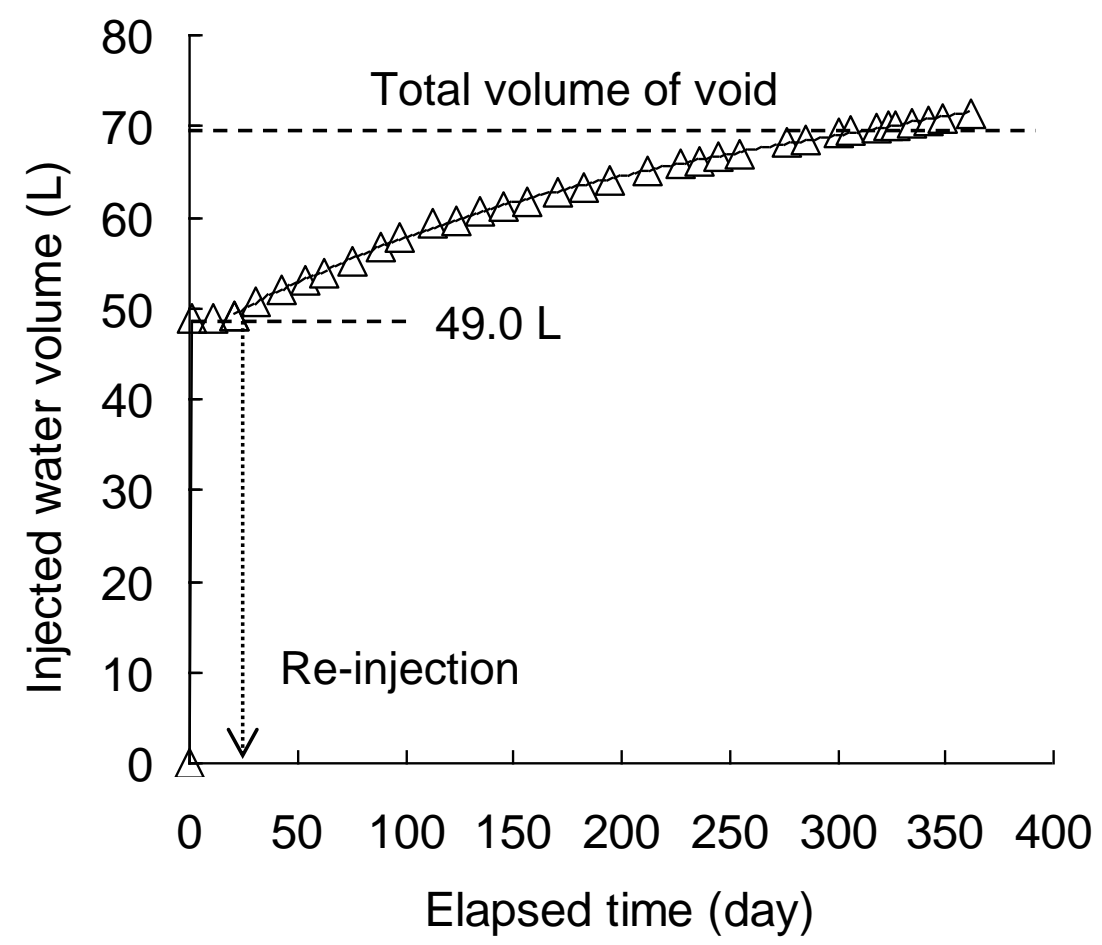

494 Figure 8. Injected water volume versus time.

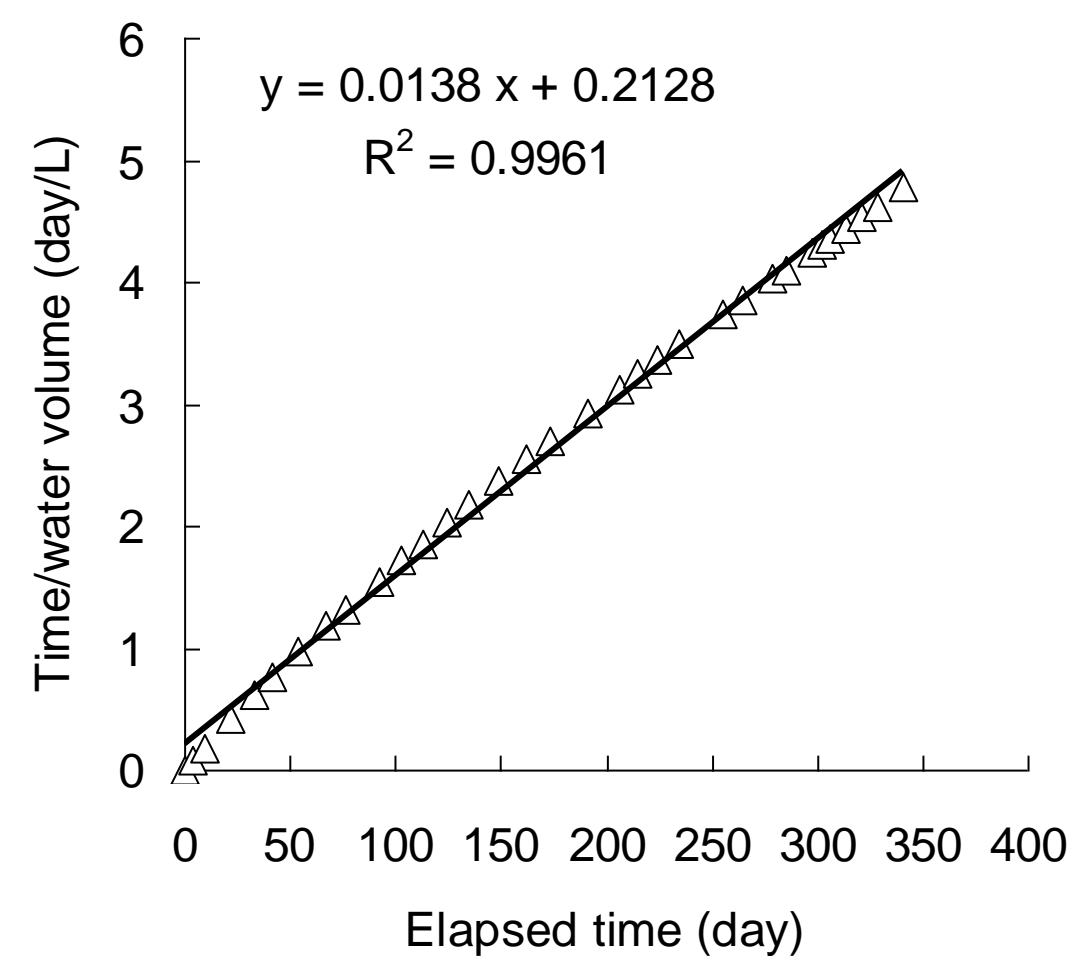

496

Figure 9. Time/water volume versus elapsed time after water rejection. 


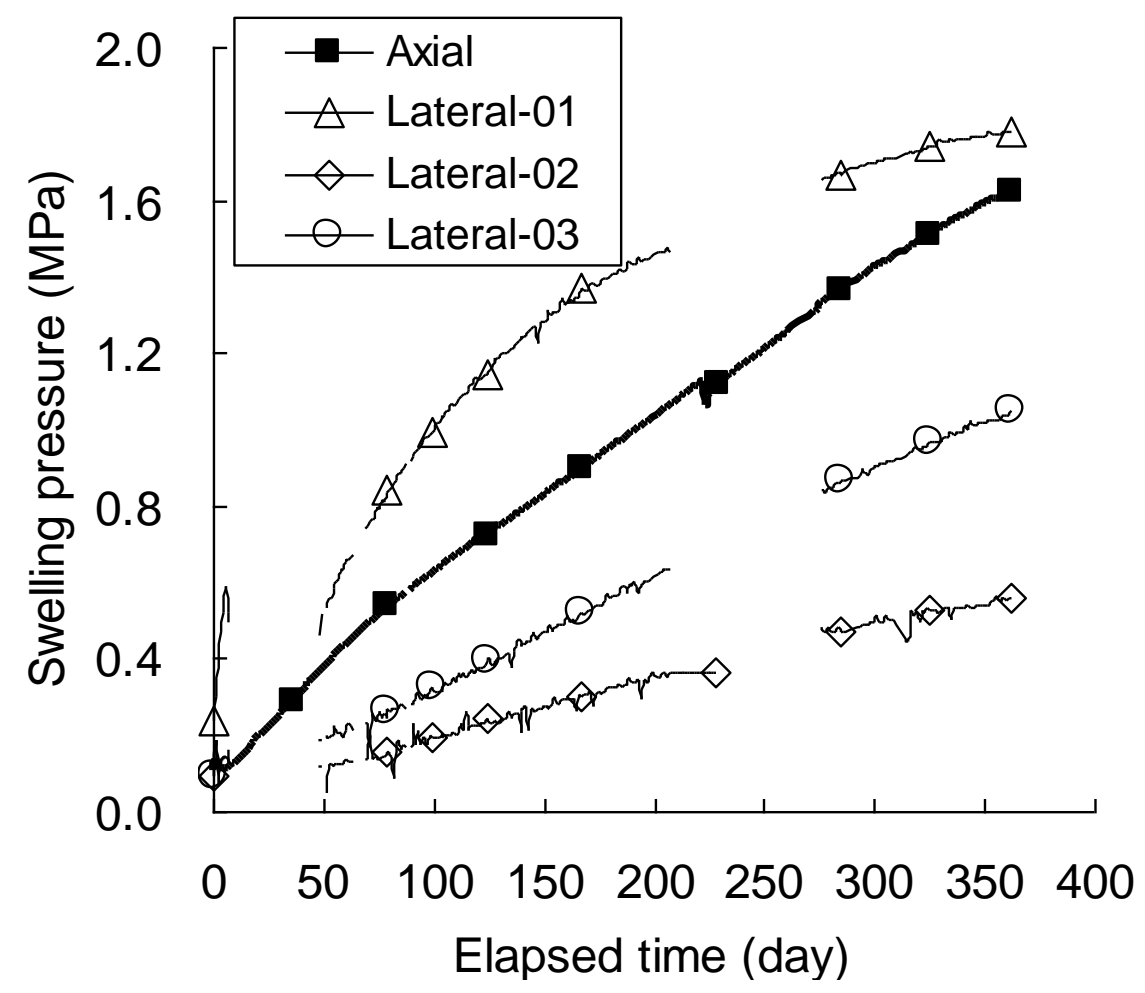

498

Figure 10. Evolution of swelling pressure.

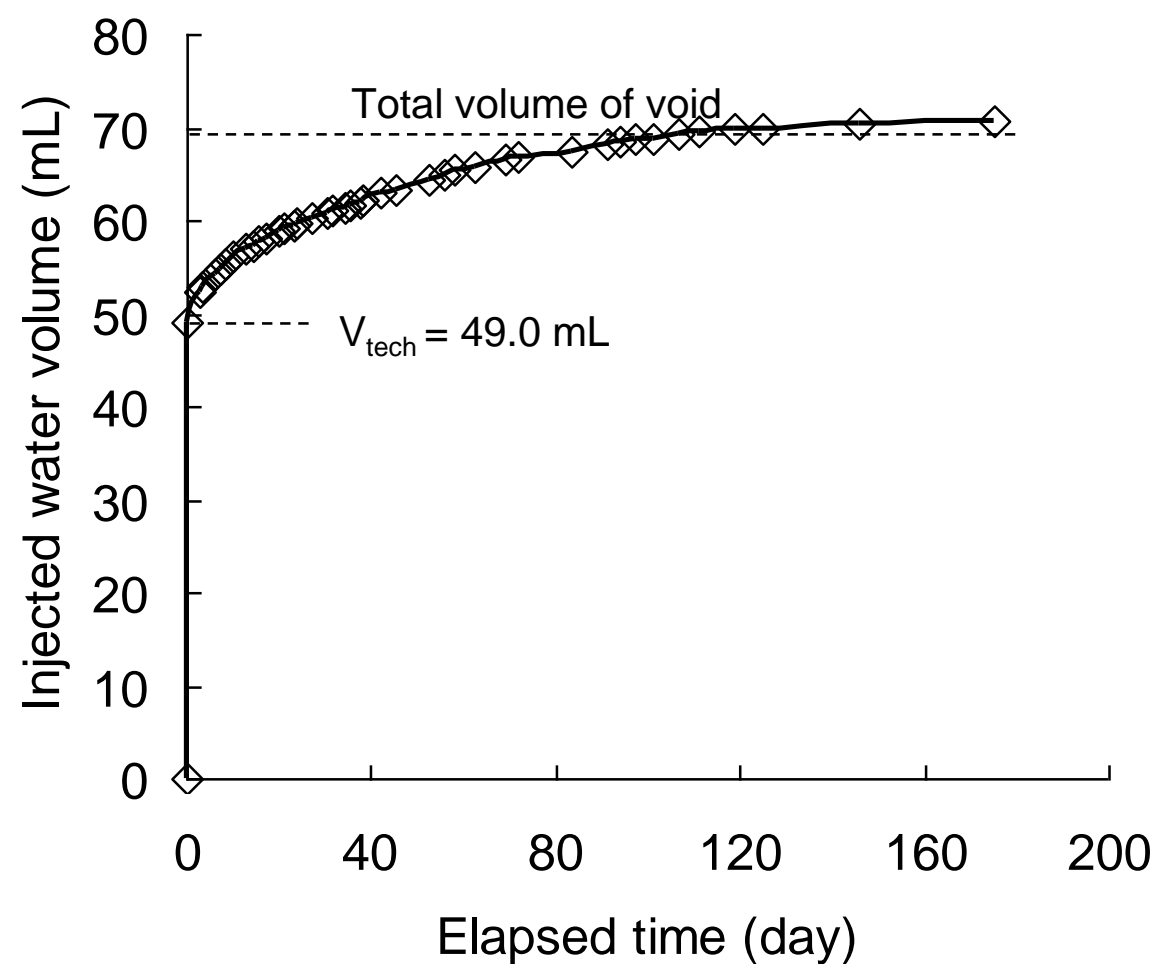

500

Figure 11. Water volume injected into the specimen. 


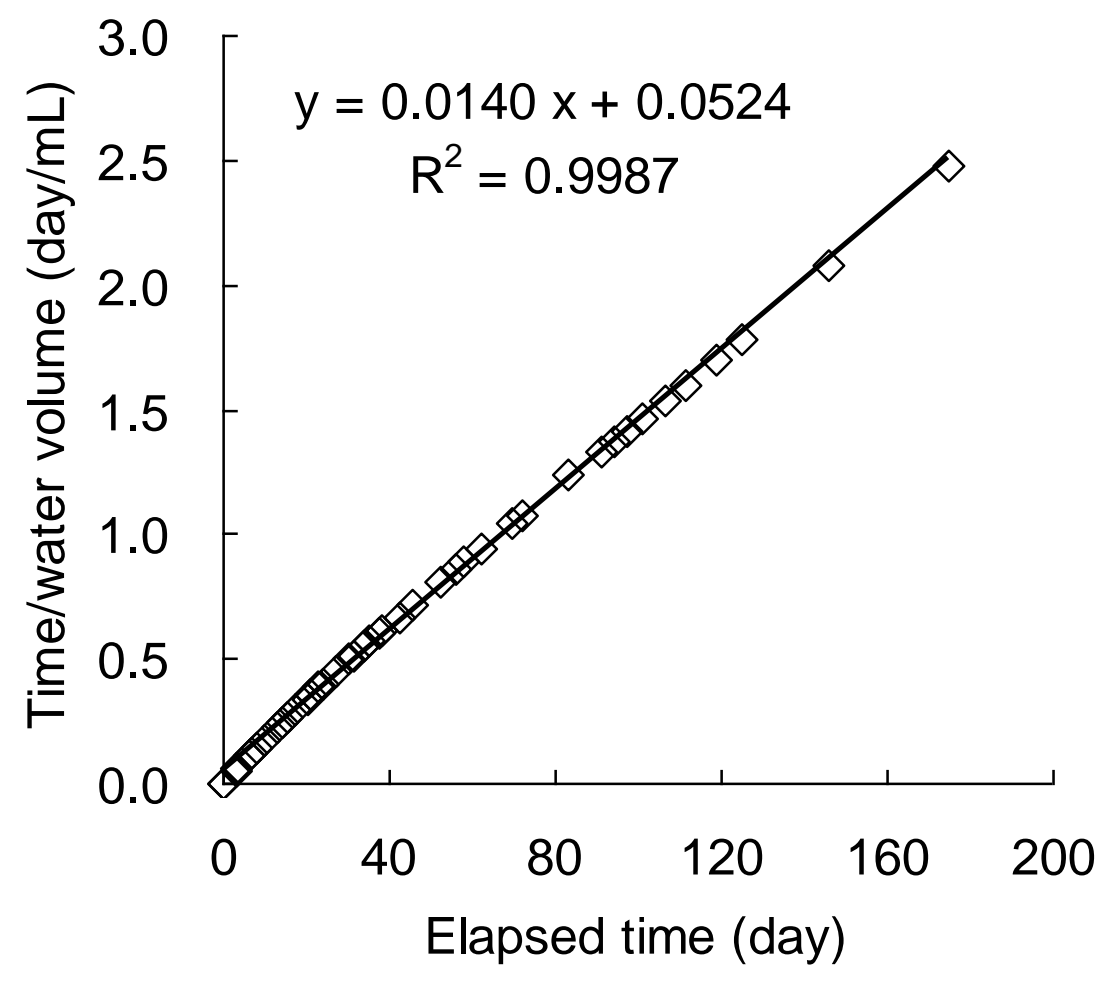

Figure 12. Time/water volume versus elapsed time.

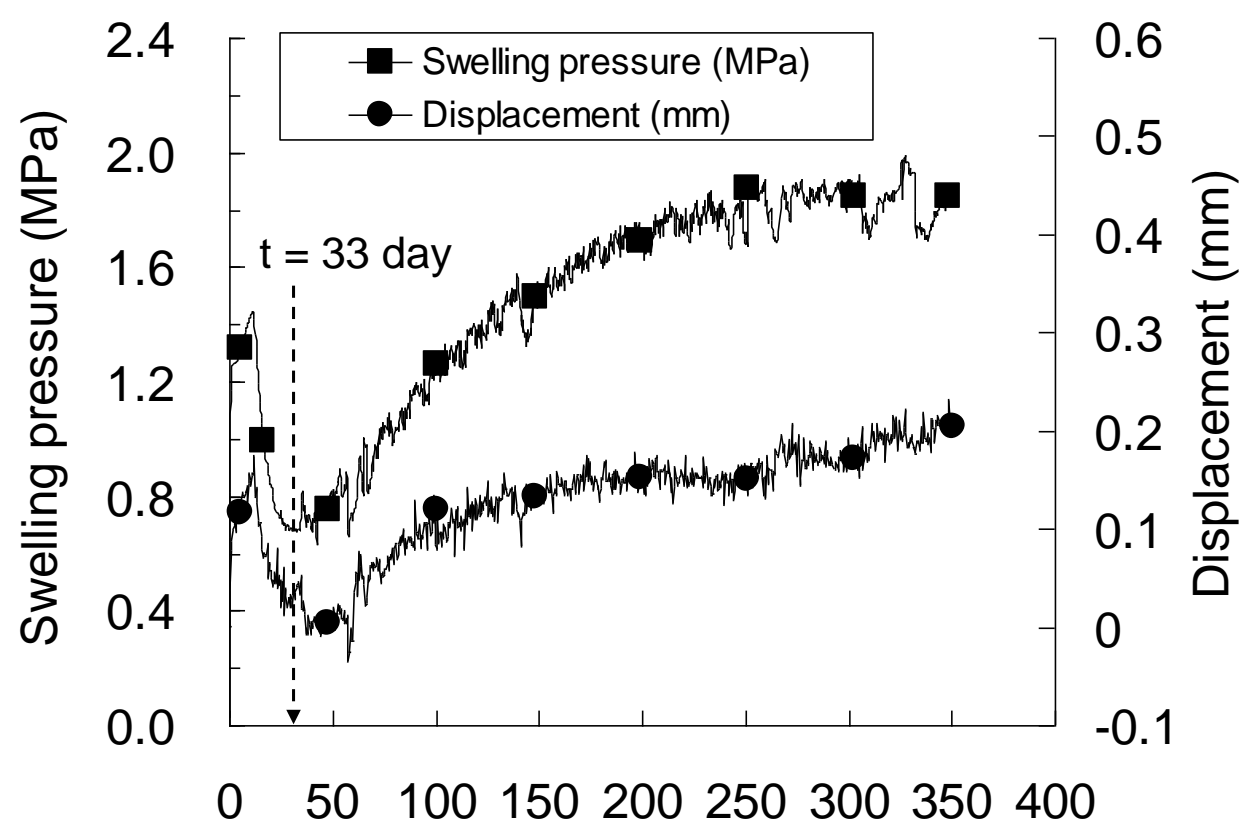

\section{Elapsed time (day)}

Figure 13. Evolution of axial swelling pressure and displacement in the first stage. 


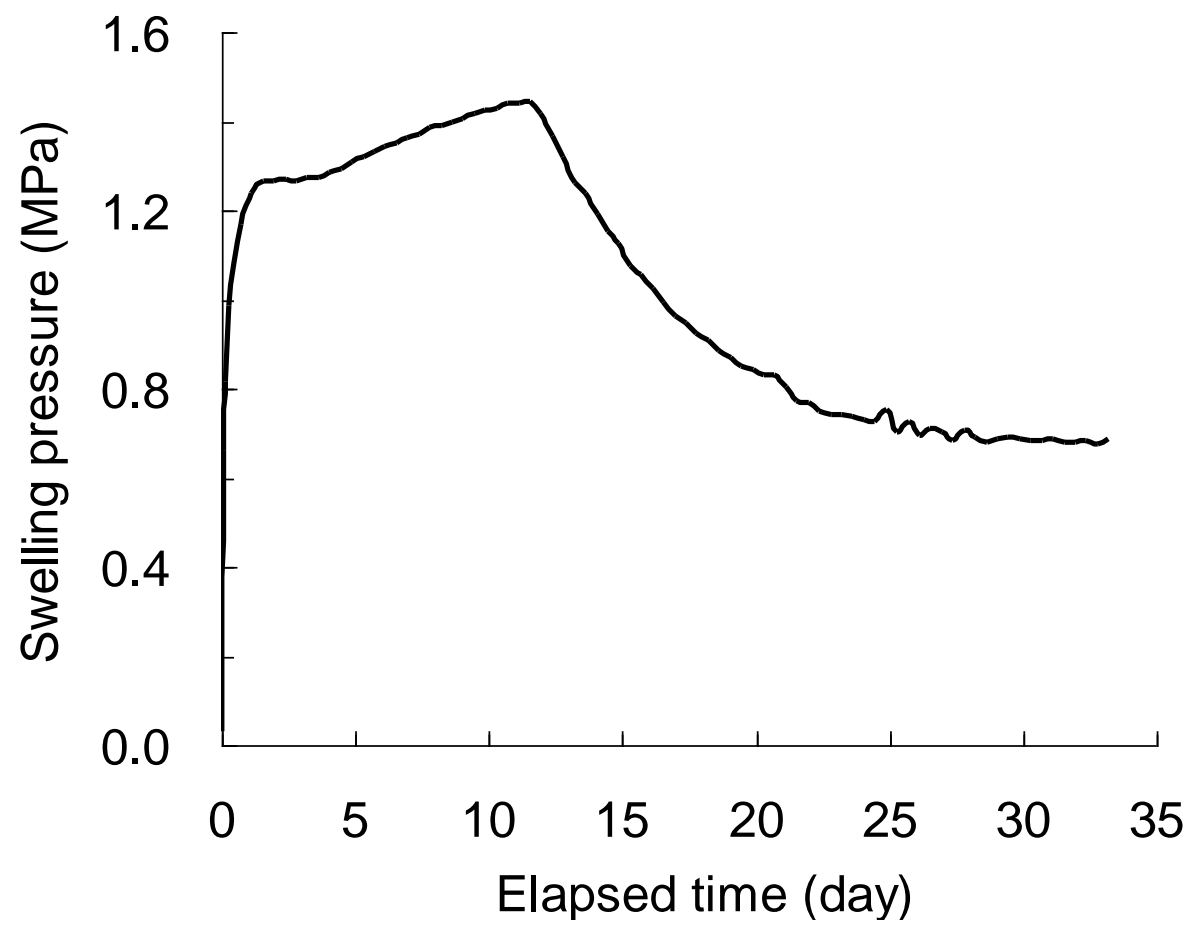

Figure 14. Evolution of swelling pressure during the first 33 days.

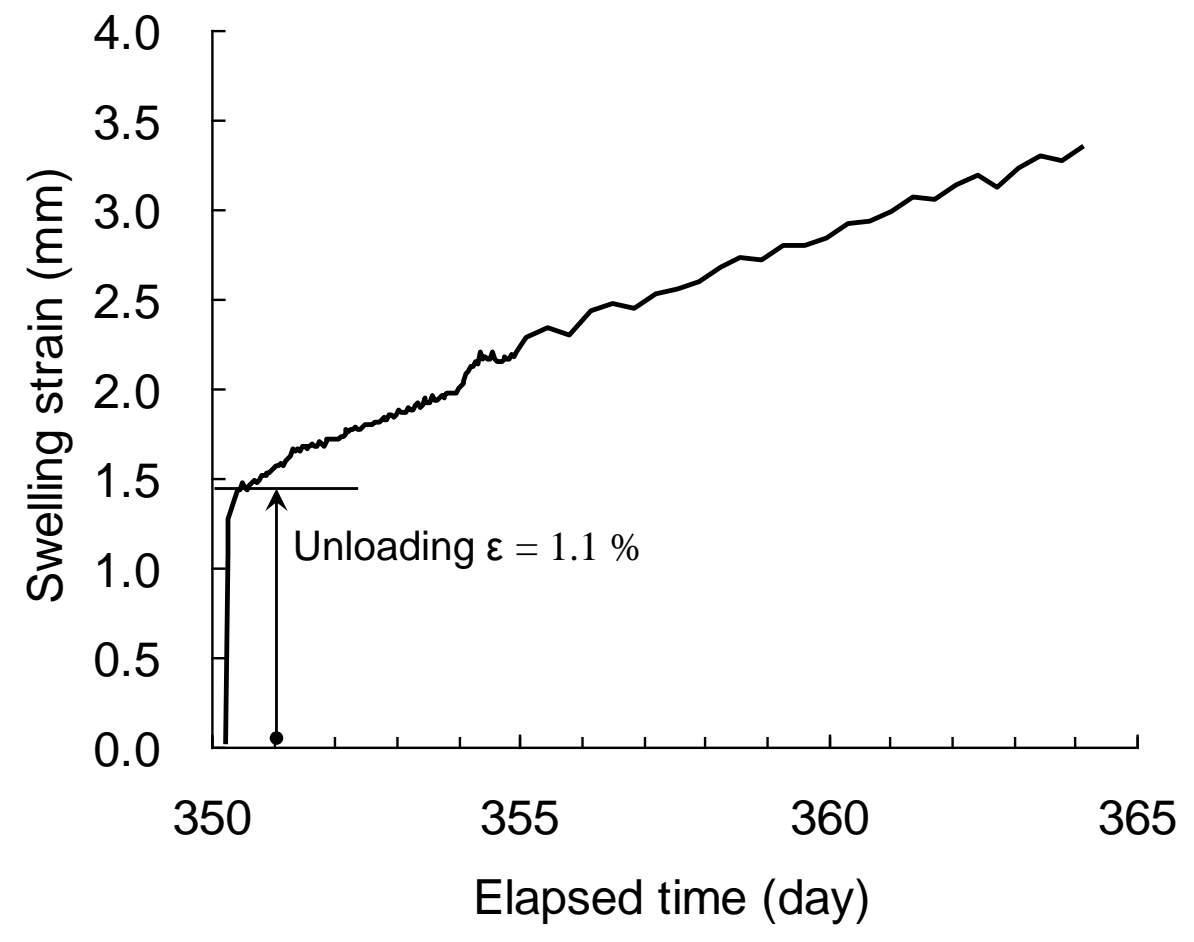

(a) Evolution of axial swelling strain during the first 15 days after unloading. 


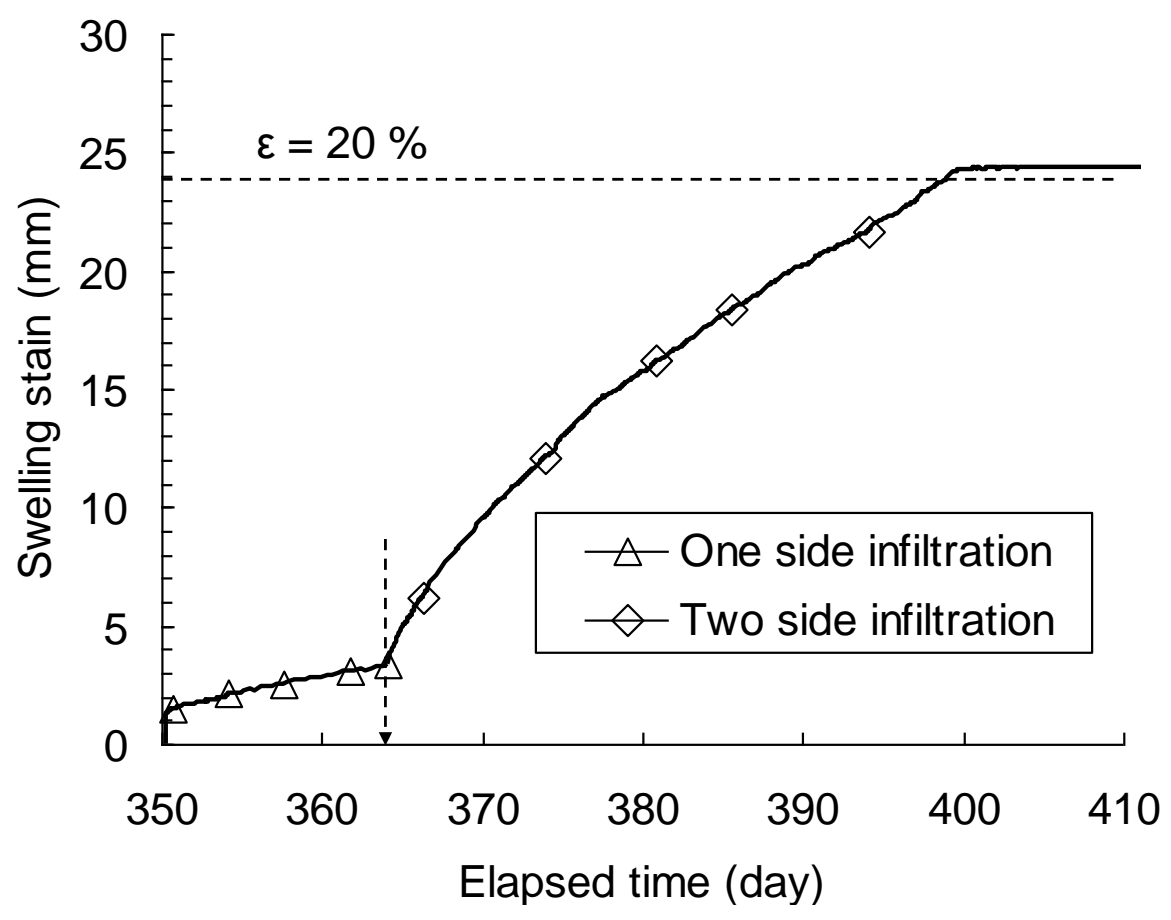

(b) Evolution of axial swelling strain

Figure 15. Evolution of axial swelling strain during Stage 2.

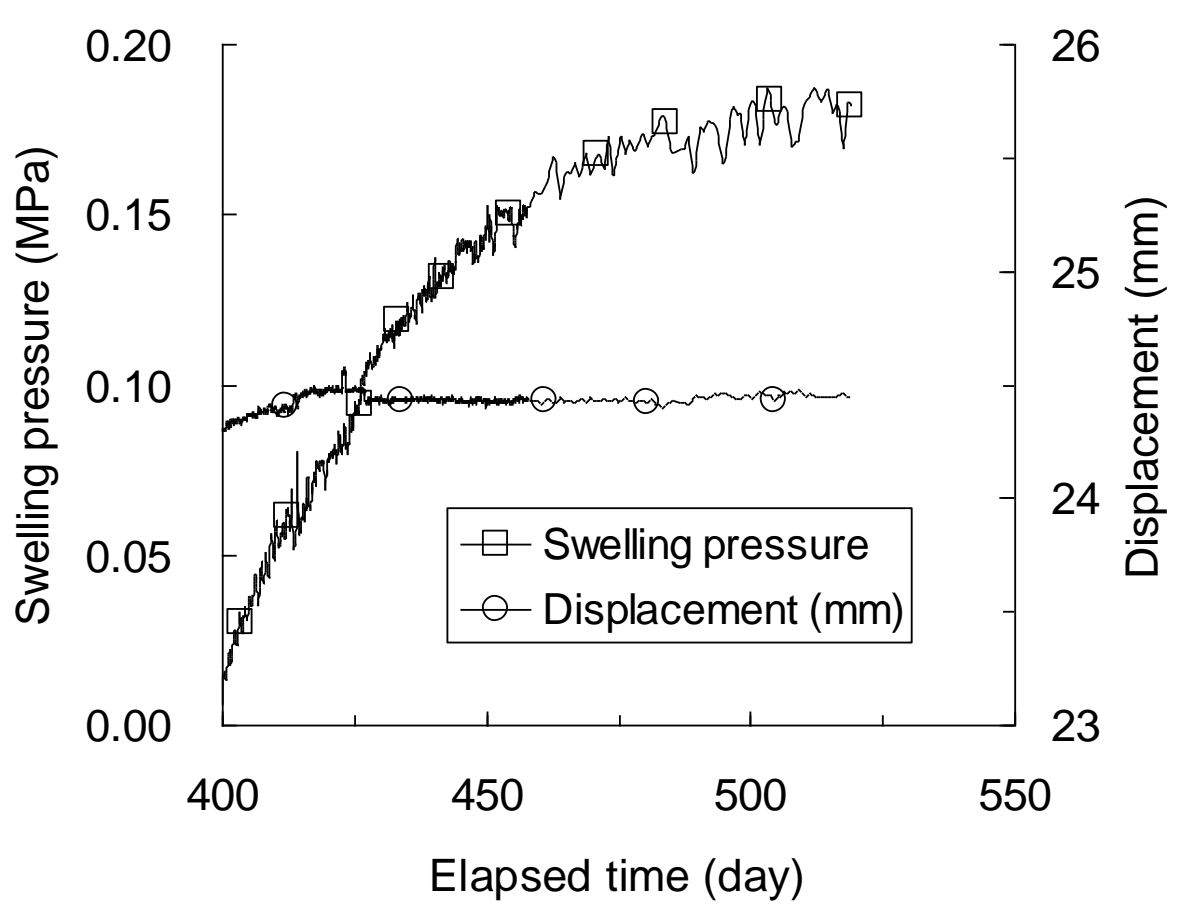

Figure 16. Evolution of axial swelling pressure during Stage 3. 


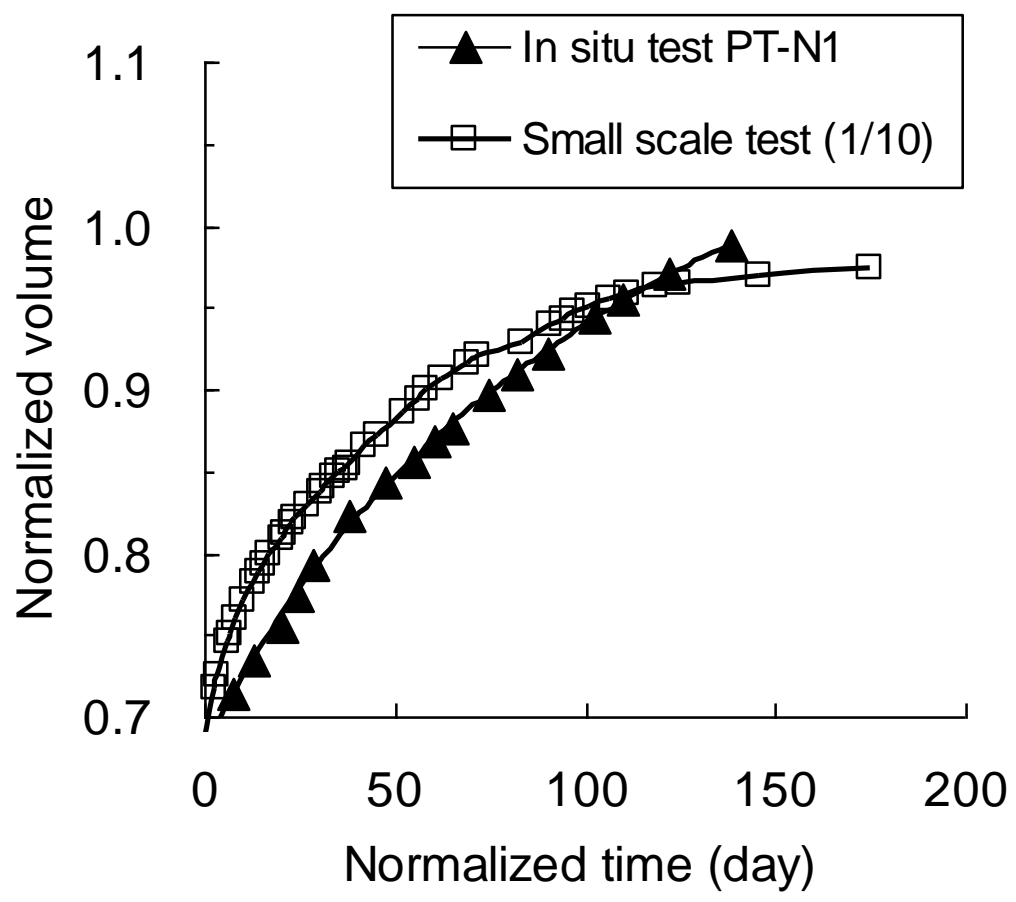

Figure 17 . Normalized water volume versus normalized time.

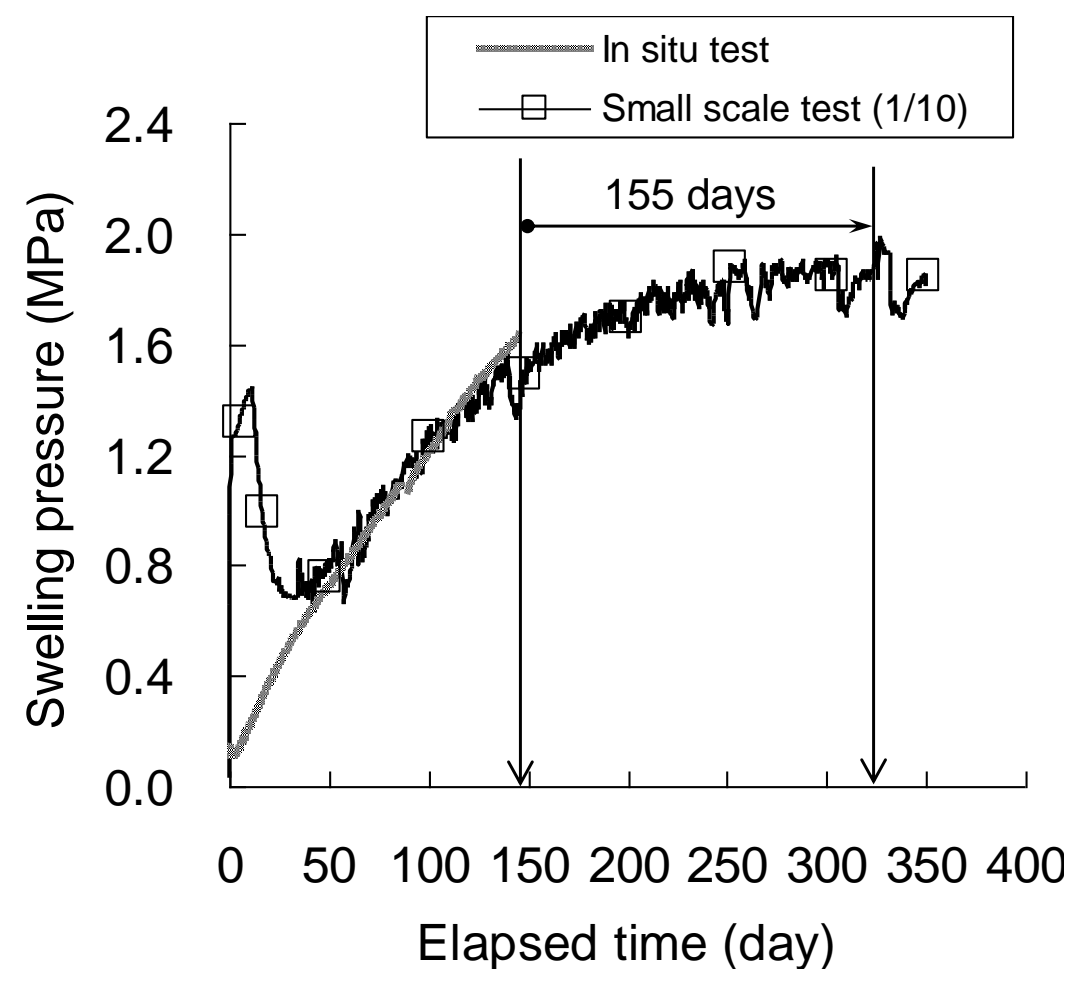

